Revista Brasileira de Agricultura Irrigada v.8, nº. 4, p.321 - 333, 2014

ISSN 1982-7679 (On-line)

Fortaleza, CE, INOVAGRI - http://www.inovagri.org.br

DOI: $10.7127 /$ rbai.v8n400239

Protocolo 239/14 - 02/04/2014 Aprovado em 26/06/2014

\title{
MICRONUTRIENTES E REAÇÃO DE UM LATOSSOLO CULTIVADO COM CANA-DE-AÇÚCAR FERTIRRIGADA
}

\author{
Renato Campos de Oliveira ${ }^{1}$, Fernando Nobre Cunha ${ }^{1}$, Piero Iori ${ }^{2}$, Marconi Batista \\ Teixeira $^{3}$, Frederico Antonio Loureiro Soares ${ }^{3}$, Glauber José de Castro Gava ${ }^{4}$
}

\begin{abstract}
RESUMO
O uso da fertirrigação na cultura da cana-de-açúcar pode causar grandes alterações nos atributos químicos do solo. Sendo assim, o objetivo deste estudo foi avaliar as alterações nos atributos químicos do solo relativo à reação do solo e aos micronutrientes do solo cultivado com cana-de-açúcar fertirrigada com nitrogênio e potássio em diferentes níveis de reposição hídrica. Este experimento foi implantado em área experimental pertencente ao Instituto Federal Goiano - Campus Rio Verde - GO, em um Latossolo Vermelho distrófico. Foi utilizada a variedade de cana-de-açúcar RB 855453, irrigada com diferentes níveis de reposição hídrica (0, 25, 50, 75 e 100\% da necessidade hídrica da cultura), combinados com e sem aplicação de nitrogênio (0 e 100 $\mathrm{kg} \mathrm{ha}^{-1}$ de N) na forma de ureia. Foi avaliada a produtividade média de cana-de-açúcar e foram analisados os teores de boro, zinco, cobre, ferro, manganês, hidrogênio + alumínio, matéria orgânica, capacidade de troca catiônica, saturação por bases e pH no solo, após a aplicação do adubo nitrogenado em duas camadas do solo, superficial ( 0 a $0,30 \mathrm{~m})$ e subsuperficial $(0,30$ a $0,60 \mathrm{~m})$. O uso da fertirrigação combinada com diferentes lâminas de reposição hídrica promoveram alterações químicas no solo, tanto no aspecto de reação do solo quantos nos teores de micronutrientes. O fator nível de reposição hídrica causou efeito significativo na alteração dos teores de cobre, ferro, hidrogênio + alumínio e capacidade de troca catiônica. A fertirrigação influenciou significativamente os teores de zinco, hidrogênio + alumínio, saturação por bases e pH no solo, sendo que provocou maior acidificação do solo. As maiores alterações nos atributos químicos do solo foram observadas em função das camadas do solo analisadas.
\end{abstract}

\footnotetext{
${ }^{1}$ Graduando em Agronomia, Instituto Federal de Educação, Ciência e Tecnologia - Câmpus Rio Verde. Rodovia Sul Goiana km 01, CEP 75901-970, Rio Verde, GO.

2 Engenheiro Agrônomo, Doutor em Ciência do Solo, Professor, Universidade Estadual Paulista UNESP - Campus Experimental de Registro. Rua Nelson Brihi Badur, 430, CEP 11900-000, Registro, SP.

${ }^{3}$ Engenheiro Agrônomo, Doutor em Agronomia, Professor, Instituto Federal de Educação, Ciência e Tecnologia - Câmpus Rio Verde. Rodovia Sul Goiana km 01, CEP 75901-970, Rio Verde, GO.

${ }^{4}$ Engenheiro Agrônomo, Doutor em Agronomia, APTA-Jaú.
} 
O uso da fertirrigação proporcionou maiores rendimentos de produtividade à cana-deaçúcar.

Palavras - chave: fertirrigação, micronutriente, acidez do solo, Saccharum officinarum L.

\title{
SOIL MICRONUTRIENTS AND SOIL REACTION CULTIVED WITH IRRIGATED SUGAR CANE
}

\begin{abstract}
The use of fertigation on sugar-cane can promote changes in soil chemistry. Thus, the aim of this study was to evaluate changes in soil micronutrients and soil reaction in sugar cane plantation with nitrogen and potassium fertigation at different levels. This experiment was carried out in an Oxisol from the experimental area of Federal Institute of Education, Science and Technology Goiano - Goiás State. Was used RB 85-5453 sugar cane variety and irrigated with different levels (0, 25, 50, 75 and $100 \%$ of the crop water requirement), with and without nitrogen ( 0 and $100 \mathrm{~kg} \mathrm{~N} \mathrm{ha}^{-1}$ ). Sugar cane productivity was evaluated, as well as, the levels of boron, zinc, copper, iron, manganese, hydrogen + aluminum, soil organic matter, cation exchange capacity, base saturation and soil $\mathrm{pH}$, after nitrogen fertilizer application in surface (0 to $0.30 \mathrm{~m})$ and subsurface $(0.300 .60 \mathrm{~m})$. Fertigation combined with different irrigation levels caused soil chemical changes, both soil reaction and soil micronutrient content. Irrigation levels factor had significant effect on changing the of cation exchange capacity, hydrogen + aluminum, copper and iron contents. Fertigation factor influenced significantly zinc, hydrogen + aluminum, base saturation and soil $\mathrm{pH}$, and caused soil acidity. The biggest changes in soil chemical properties were due to soil layers analyzed. Fertigation increased the sugar cane productivity.
\end{abstract}

Keywords: fertigation, micronutrient, Saccharum officinarum L., soil acidity

\section{INTRODUÇÃO}

Atualmente, o Brasil é o maior produtor mundial de açúcar e de álcool (MAPA, 2013). Sendo assim, o agroecossistema da cana-deaçúcar tem sido foco de pesquisas por ter relativa expressão econômica e ocupação fundiária (Barros et al., 2010). A cana-deaçúcar é uma cultura com elevado grau de tecnologia aplicada ao sistema produtivo (Dalri e Cruz, 2008). Dentre as características que contribuem para o elevado grau de tecnologia aplicado a esta cultura, pode-se destacar a fertirrigação, que permite a aplicação de fertilizantes simultaneamente com a água de irrigação (Peixoto et al., 2006). A fertirrigação coloca os íons na solução do solo em forma facilmente assimilável pela cultura (Padilla, 1998).

A quantidade de nutrientes absorvida pelas plantas é função das condições edafoclimáticas e das características genéticas da planta. Glass (1989) e Marschner (1995) destacam que, entre os fatores edafoclimáticos, a disponibilidade de nutrientes e a umidade do solo têm sido consideradas as principais 
responsáveis por alterações nos padrões de absorção de nutrientes.

A fertirrigação tem sido associada à melhoria da qualidade química do solo, devido ao fornecimento de nutrientes e água no sistema. Porém, esta prática pode causar alteração e um desequilíbrio nos atributos químicos do solo, principalmente aos relacionados aos micronutrientes do solo e à reação do solo. Quando da escolha dos fertilizantes a serem utilizados via água de irrigação, características como solubilidade em água, poder de acidificação ou salinização do solo, mobilidade de nutrientes no solo, entre outras, devem ser analisadas (Burt et al., 1995; Vieira, 1998; Peixoto et al., 2006; Teixeira et al., 2007).

As variações dos nutrientes observadas no solo após o ciclo de uma determinada cultura pode fornecer, mesmo que indiretamente, informações sobre a absorção destes nutrientes pelas plantas. Peixoto et al. (2006) avaliando os efeitos da fertirrigação com potássio e nitrogênio, sobre alguns atributos químicos de um Argissolo Amarelo distrófico, verificaram que com exceção da condutividade elétrica do extrato de saturação e do potássio do solo, os atributos químicos analisados não foram influenciados pela fertirrigação.

Por outro lado, a adição de nutrientes ao solo via fertirrigação ou de outra forma, por exemplo, a vinhaça, podem incrementar alguns elementos. Barros et al. (2010) verificaram que a adição de vinhaça à lavoura de cana-deaçúcar, por dez anos, alterou positivamente as propriedades químicas do solo, proporcionando melhoria na fertilidade pelo maior aporte de macronutrientes no perfil. De forma semelhante, Teixeira et al. (2007) estudando as alterações nos atributos químicos do solo em função da fertirrigação, verificaram que o uso da técnica aumentou a acidez do solo e que essa acidificação foi proporcional à dose de adubo.

Portanto, verifica-se que a prática da fertirrigação traz efeitos ao solo, desde grandes alterações químicas até efeitos mais difusos, como citado por Teixeira et al. (2007). Sendo assim, o objetivo deste estudo foi avaliar as alterações nos atributos químicos do solo relativo à reação do solo e aos micronutrientes do solo cultivado com cana-de-açúcar fertirrigada com nitrogênio e potássio em diferentes níveis de reposição hídrica.

\section{MATERIAL E MÉTODOS}

O experimento foi implantado em área experimental pertencente ao Instituto Federal Goiano (IFGoiano) - Campus Rio Verde, GO, onde predomina relevo suavemente ondulado e clima Aw, Tropical de Savana, de acordo com a classificação de Köppen (Castro Neto, 1982), com inverno seco e verão chuvoso, temperatura média anual entre 20 e $25^{\circ} \mathrm{C}$ e média pluviométrica anual acima de $1500 \mathrm{~mm}$. O período chuvoso se estende de novembro a maio, ocasião em que são registradas mais de 80\% do total das chuvas do ano. O fenômeno "veranico" ocorre geralmente nos meses de janeiro a março, normalmente com duração de cerca de 10 a 15 dias, podendo, eventualmente, prolongar-se por um tempo maior. 
O delineamento experimental utilizado foi de blocos ao acaso, onde foram analisadas diferentes níveis de reposição hídrica $(0,25$, 50, 75 e 100\% da necessidade hídrica da cultura, baseado na evapotranspiração no período), combinados com e sem aplicação de nitrogênio (0 e $100 \mathrm{~kg} \mathrm{ha}^{-1}$ de $\mathrm{N}$ ) na forma de uréia, sendo que as características químicas foram avaliadas em duas camadas do solo ( 0 a $0,30 \mathrm{~m}$ e 0,30 a $0,60 \mathrm{~m}$ ), com quatro repetições. Assim, a reposição hídrica de $100 \%$ foi o valor de referência, ou seja, atendeu a necessidade hídrica da cultura. A Figura 1 demonstra o esquema de distribuição das parcelas correspondentes aos respectivos tratamentos na área experimental.
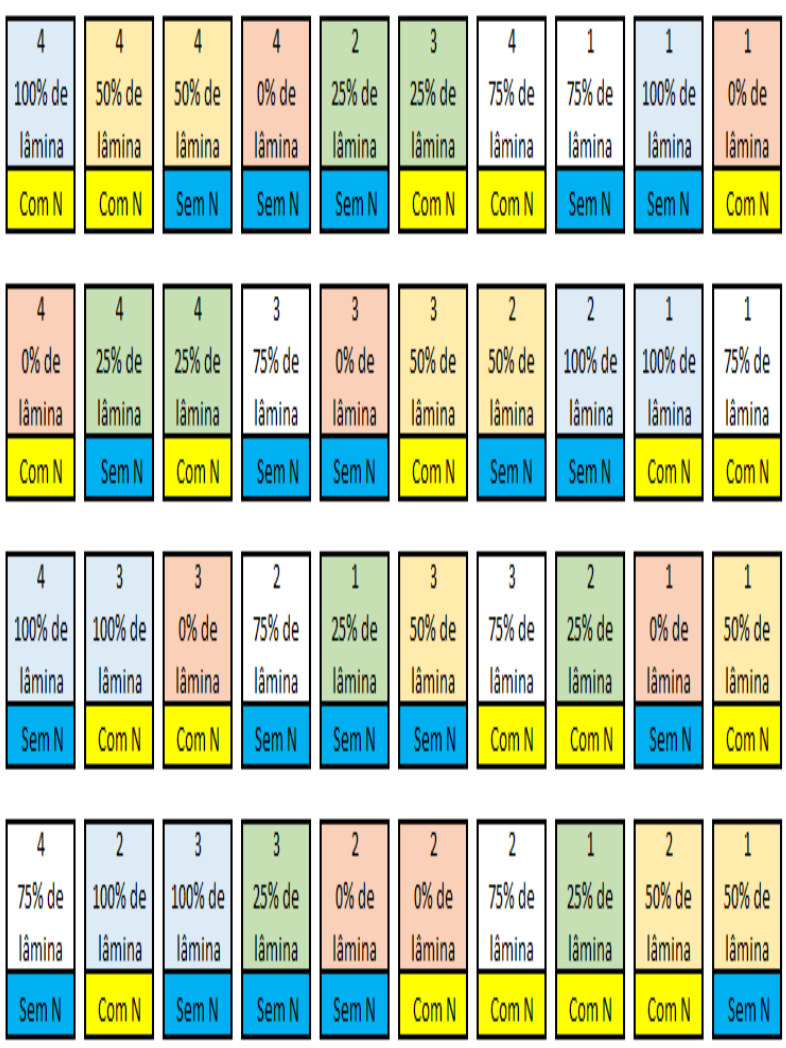

Figura 1. Esquema de distribuição das parcelas na área experimental.

O solo da área experimental foi classificado como Latossolo Vermelho distro- férrico (LVdf) de textura média (Embrapa, 2006). Na Tabela 1 são apresentados os dados da análise química do solo amostrado anteriormente a implantação do experimento.

Tabela 1. Características químicas do solo, nas camadas de $0-0,30$ e 0,30 - 0,60 m de profundidade

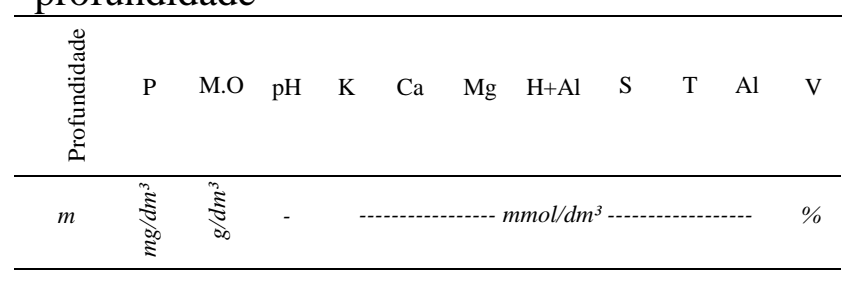



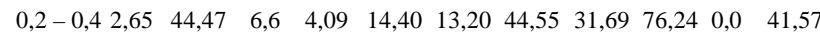

$\mathrm{pH}$ em água destilada, g $100 \mathrm{~cm}^{-3}$ de terra. Extrator de P, K e micronutrientes - Mehlich ${ }^{-1}$. M.O - Matéria orgânica, $\mathrm{g} / \mathrm{dm}^{3}$. T - Capacidade de troca de cátions, $\mathrm{S}+$ $\mathrm{H}+\mathrm{Al}$. V - Porcentagem de saturação de bases, V=100 $\mathrm{S} / \mathrm{T}$.

O preparo inicial do solo consistiu de gradagem prévia para eliminar a vegetação existente, distribuição mecânica de calcário na dosagem de 2,0 $\mathrm{t} \mathrm{ha}^{-1}$ e posterior gradagem para incorporar o calcário e destorroar o solo. Por último, foi feita uma gradagem de nivelamento. Para a construção dos sulcos de plantio, utilizou-se de subsolagem e posterior retirada de solo, formando o leito de plantio.

O plantio ocorreu no dia 15 de março de 2011. Foram implantadas parcelas experimentais, constituídas de três sulcos de linha dupla (espaçamento combinado tipo abacaxi) com espaçamento de 0,40 metros entre linhas na fileira dupla, 1,40 $\mathrm{m}$ entre as fileiras duplas e 8 metros de comprimento, totalizando $35,2 \mathrm{~m}^{2}$ de área total. Foi plantada a variedade RB 85-5453, que tem, como características principais, alto teor de açúcar e precocidade. 
Seguindo recomendações de Sousa e Lobato (2004) e conforme o resultado da análise de solo as parcelas fertirrigadas foram corrigidas com aplicação de $30 \mathrm{~kg} \mathrm{ha}^{-1}$ de nitrogênio, $120 \mathrm{~kg} \mathrm{ha}^{-1}$ de $\mathrm{P}_{2} \mathrm{O}_{5}$ e $80 \mathrm{~kg} \mathrm{ha}^{-1}$ de $\mathrm{K}_{2} \mathrm{O}$. Cinco tratamentos não receberam aplicação de nitrogênio (parcelas sem fertirrigação). A adubação potássica foi realizada parcialmente no plantio, representando 30\% do total, o restante foi aplicado via água de irrigação ao longo da condução do experimento. Para as parcelas em que foi prevista a aplicação de nitrogênio e potássio, estes foram aplicados totalmente via fertirrigação, ou seja, foram dissolvidos em água e fornecidos para as plantas via sistema de irrigação.

Para os tratamentos com reposição hídrica, foi utilizado o sistema de irrigação por gotejamento subsuperficial (através de um injetor Venturi), utilizando-se um tubo gotejador localizado e enterrado a 0,20 m de profundidade da superfície do solo, no meio da linha dupla. As características técnicas do tubo gotejador utilizado são as seguintes: tubo gotejador de parede delgada, vazão de 1,0 L h 1 , pressão de 1,0 bar e espaçamento entre gotejadores de $0,50 \mathrm{~m}$.

Foi avaliada a produtividade média de colmos da cana-de-açúcar ( $\mathrm{t} \mathrm{ha}^{-1}$ ) ao fim do experimento (410 dias após plantio), mediante a colheita dos colmos da área útil das parcelas. Ao fim do experimento foram coletadas amostras de solo nas camadas de $0-0,30$ m e 0 30-0,60 $\mathrm{m}$ de profundidade e realizada a análise química, sendo analisados os teores de boro $(\mathrm{B})$, zinco $(\mathrm{Zn})$, cobre $(\mathrm{Cu})$, ferro $(\mathrm{Fe})$, manganês (Mn), hidrogênio + alumínio $(\mathrm{H}+\mathrm{Al})$, matéria orgânica (MO), capacidade de troca catiônica (CTC), saturação por bases (V) e potencial hidrogeniônico $(\mathrm{pH})$ do solo. As análises químicas do solo foram realizadas seguindo metodologia descrita por Vettori (1969) e Embrapa (1997).

Os resultados foram inicialmente avaliados pela análise de variância e teste $\mathrm{F}$, considerando os diferentes usos do solo como fatores de variação. Em caso de significância, foi realizada a comparação entre as médias de áreas fertirrigadas e não fertirrigadas pelo teste de Scott e Knott (1974), a 5\% de probabilidade, e para os níveis de irrigação foram realizadas análises de regressão por ser uma variável quantitativa.

\section{RESULTADOS E DISCUSSÃO}

É apresentada na figura 2 a produtividade média de cana-de-açúcar os diferentes níveis de reposição hídrica. Verificouse que a produtividade de cana-de-açúcar sofreu interferência significativa da irrigação, ou seja, a produtividade da cana-deaçúcar tendeu a aumentar com o aumento dos níveis de água até um valor máximo estimado de $235 \mathrm{t} \mathrm{ha}^{-1}$ para 69\% da reposição hídrica via irrigação. O uso da fertirrigação também apresentou efeito positivo no rendimento da cana-de-açúcar, onde os tratamentos que receberam o adubo nitrogenado apresentaram maior produtividade média de cana-de-açúcar em relação às parcelas sem o uso da fertirrigação (Figura 2). Este efeito positivo na produtividade de cana-de-açúcar se deve ao fato de o nutriente ser fornecido 
juntamente com a água, que é essencial para sua absorção. Além disso, as parcelas fertirrigadas apresentaram uma melhor distribuição do fertilizante no campo e, possibilitou um maior parcelamento das adubações, o que aumentou a eficiência na utilização dos adubos pelas plantas (Duenhas et al., 2002). Resultados semelhantes foram obtidos por Dalri e Cruz (2008), que também verificaram maiores produtividades de canade-açúcar fertirrigada via irrigação em subsuperfície, e por Andrade Júnior et al. (2012), que trabalhando com cana-de-açúcar fertirrigada por gotejamento subsuperficial, também verificaram incremento na produtividade com a aplicação de nitrogênio.

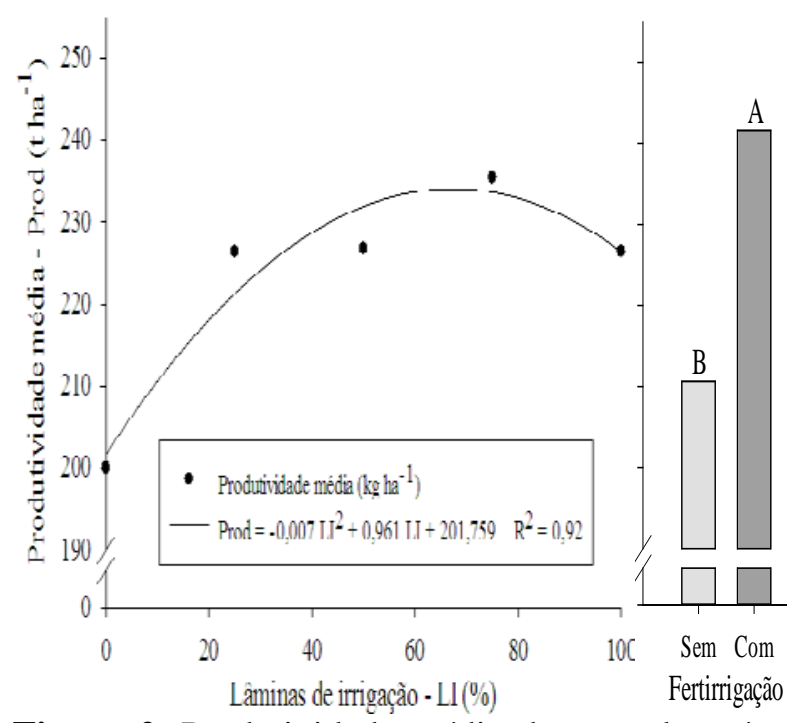

Figura 2. Produtividade média da cana-de-açúcar em função dos diferentes níveis de reposição hídrica e em função da fertirrigação com $\mathrm{N}$ e K. Letras diferentes entre colunas diferem entre si, ao nível de 5\%, pelo teste de Scott-Knott.

O resumo da análise de variância (Tabela 2) revelou diferença significativa dos fatores estudados para a maioria dos atributos químicos do solo. Apenas o teor de boro não foi diferiu estatisticamente para nenhum fator estudado, bem como a interação destes fatores. $\mathrm{O}$ fator reposição hídrica $(\mathrm{RH})$ foi significativo para os teores de cobre, ferro, hidrogênio + alumínio e para capacidade de troca catiônica do solo. $O$ fator fertirrigação (F) influenciou significativamente nos teores de zinco, hidrogênio + alumínio, na saturação por bases e no $\mathrm{pH}$ do solo. Quando analisado o efeito do fator camada do solo (C), a análise de variância indicou efeito significativo nos teores de cobre, manganês, hidrogênio + alumínio, matéria orgânica, na capacidade de troca catiônica e no $\mathrm{pH}$ do solo. A única interação entre fatores que afetou significativamente os resultados dos atributos químicos estudados foi $\mathrm{RH} \times \mathrm{F}$, provocando interferência significativa nos teores de hidrogênio + alumínio e na capacidade de troca catiônica.

Tabela 2. Resumo da análise de variância para os atributos químicos do solo cultivado com cana-de-açúcar submetida a diferentes níveis de reposição hídrica, com e sem fertirrigação com N e K

\begin{tabular}{|c|c|c|c|c|c|c|c|c|c|}
\hline \multirow{2}{*}{ FV } & \multicolumn{9}{|c|}{ Quadrados Médio } \\
\hline & $\underline{\mathrm{Zn}}$ & $\mathrm{Cu}$ & $\mathrm{Fe}$ & $\mathrm{Mn}$ & $\mathrm{H}+\mathrm{Al}$ & CTC & $\mathrm{V}$ & $\mathrm{MO}$ & $\overline{\mathrm{pH}}$ \\
\hline $\mathrm{RH}$ & NS & $5,6^{* *}$ & $5,6^{* *}$ & NS & $4,5^{*}$ & $5,8^{* *}$ & NS & NS & NS \\
\hline $\mathrm{F}$ & $14,8^{* *}$ & NS & NS & NS & $9,4^{* *}$ & NS & $4,9^{*}$ & NS & $5,41^{*}$ \\
\hline C & NS & $23,4^{*}$ & * NS & $21,4^{* *}$ & $57,6^{* *}$ & $85,9^{* *}$ & NS & $11,9^{* *}$ & $15,4^{*}$ \\
\hline RHxF & NS & NS & NS & NS & $10,6^{* *}$ & $7,7^{* *}$ & NS & NS & NS \\
\hline RHxC & NS & NS & NS & NS & NS & NS & NS & NS & NS \\
\hline FxC & NS & NS & NS & NS & NS & NS & NS & NS & NS \\
\hline RHxFxC & NS & NS & NS & NS & NS & NS & NS & NS & NS \\
\hline $\mathrm{CV}$ & & & & & & & & & \\
\hline $\begin{array}{l}\text { RH - } \\
\text { solo; } \\
\text { signif } \\
\text { signif } \\
\text { signif }\end{array}$ & $\begin{array}{l}\text { reposi } \\
\text { CV } \\
\text { icativ } \\
\text { icativ } \\
\text { icativ }\end{array}$ & Ição & nídric & $\begin{array}{l}\mathrm{a} ; \mathrm{F}- \\
\text { iente } \\
\text { el de } \\
\text { de } 5 \%\end{array}$ & $\begin{array}{l}\text { fertir } \\
\text { de } \\
1 \% \\
0 \text { de p }\end{array}$ & $\begin{array}{l}\text { ação } \\
\text { riaçã } \\
\text { pro } \\
\text { babil }\end{array}$ & $\mathrm{C}-$ & $\begin{array}{l}\text { ada } \\
\text { ); ** } \\
\text { ade; * } \\
\mathrm{e}^{\mathrm{NS}} \text { : }\end{array}$ & $\begin{array}{l}\text { do } \\
\text { - } \\
\text { ào }\end{array}$ \\
\hline
\end{tabular}


Verificou-se ainda que para os teores de cobre, hidrogênio + alumínio e para a capacidade de troca catiônica, houve a influência significativa de mais de um fator e/ou interação de fatores. Foi possível constatar ainda que a camada de solo, superficial e subsuperficial, foi o fator que mais influenciou nos atributos químicos do solo (Tabela 2), devido principalmente aos distintos valores de matéria orgânica do solo entre as duas camadas, pois a matéria orgânica do solo responde por grande parte da capacidade de troca de cátions do solo dos micronutrientes nos solos tropicais. Em estudo utilizando fertirrigação com vinhaça, Barros et al. (2010) também verificaram variações estatísticas nos micronutrientes tanto no uso da técnica, quanto para as camadas do solo.

$\mathrm{Na}$ figura 3 são apresentadas as regressões entre os teores médios de cobre e ferro no solo para os diferentes níveis de reposição hídrica. Os teores de cobre e ferro no solo apresentaram comportamento idêntico, sendo que os maiores teores foram obtidos nos tratamentos em que não receberam água de irrigação ( $0 \%$ de reposição hídrica). As duas regressões ajustadas entre teores de cobre ou ferro foram do tipo quadrática, em que, os menores valores encontrados no solo para o cobre foi de 2,78 $\mathrm{mg} \mathrm{dm}^{-3}$ e de $27 \mathrm{mg} \mathrm{dm}^{-3}$ para o ferro, com 63 e 55\% das lâminas de irrigação, respectivamente.
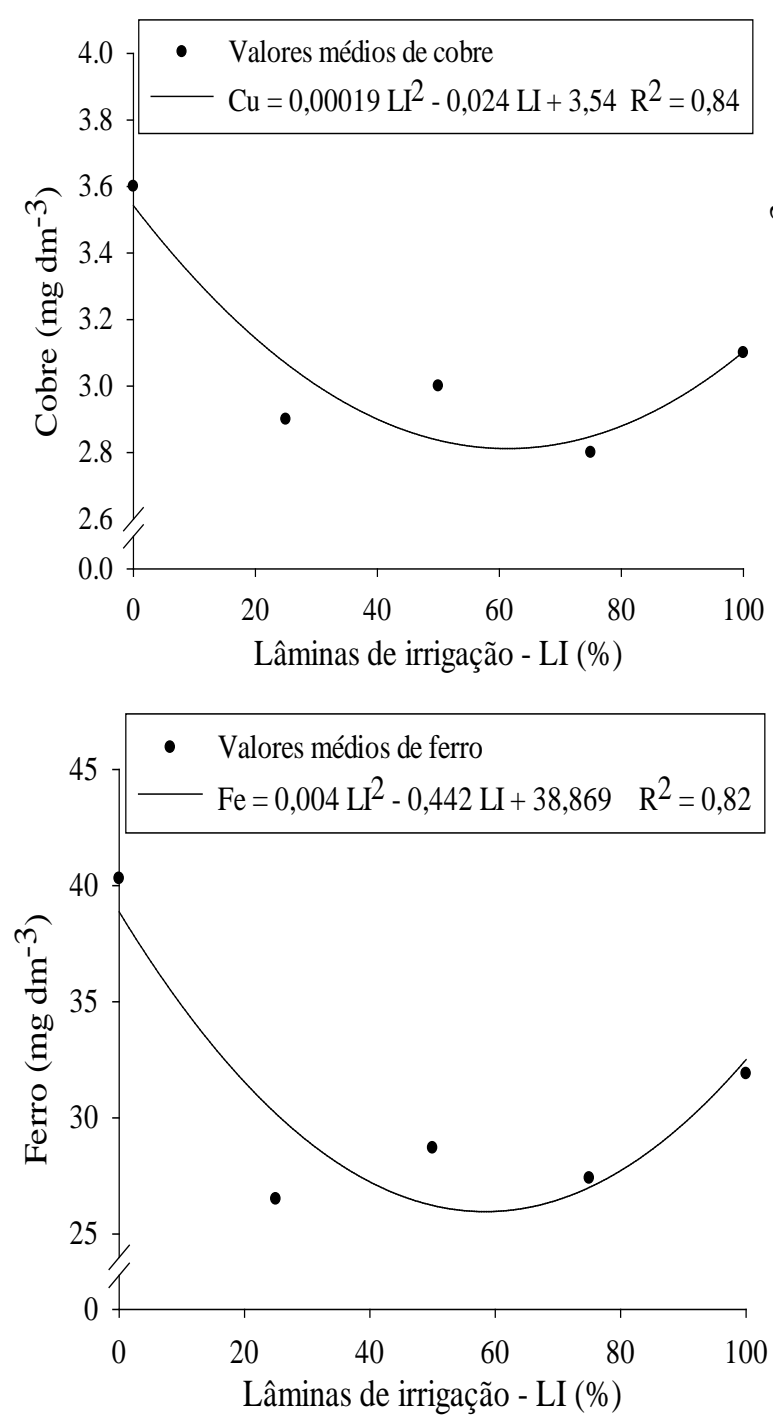

Figura 3. Teores médios de cobre e ferro no solo em função dos níveis de reposição hídrica.

O cobre é o elemento menos móvel no solo, dentre os micronutrientes, devido a sua forte adsorção nos colóides orgânicos e inorgânicos do solo (Abreu et al., 2007), evidenciando que as menores quantidades deste elemento e de ferro no solo se deram principalmente pela maior absorção pelas plantas de cana-de-açúcar nos tratamentos com reposição hídrica, podendo estar relacionado aos maiores rendimentos de produtividade da 
cana-de-açúcar com o uso da irrigação, o que acarretou numa maior absorção de cobre e, consequentemente, menor quantidade deste elemento no solo.

Para o teor de ferro no solo, os resultados podem se constituir num problema não somente pela deficiência, mas também pelo efeito inverso, ou seja, a toxicidade deste elemento às plantas. $\mathrm{O}$ problema de toxicidade do ferro às plantas pode se agravar com o efeito da água. Estes problemas se dão em ambientes onde há o manejo da água, como por exemplo, na utilização da técnica de irrigação (tabela 2) ou com problemas naturais com a água, como por exemplo, excesso de chuvas. Observando sintomas de toxicidade de ferro em soja, Bataglia e Mascarenhas (1981) verificaram que a toxicidade estava associada ao excesso de chuvas no local, e indicaram que a provável causa desse aumento temporário da absorção de ferro se deve ao aumento de concentração do íon $\mathrm{Fe}^{2+}$ na solução do solo em condições redutoras criadas pelo excesso de chuvas. Sendo assim, vale salientar que em estudos que envolvam reposição hídrica no solo deve se realizar um acompanhamento do teor de ferro no solo. Porém, vale ressaltar a adequada manutenção da umidade do solo em cultivos irrigados e, existindo viabilidade, a utilização de irrigação suplementar durante o período de deficiência hídrica na época chuvosa para culturas de sequeiro, é indicada por Fageria (1998) como uma das recomendações específicas para aumentar a eficiência nutricional das plantas.
Os teores médios de zinco, saturação por bases e pH do solo em função do uso ou não da fertirrigação são apresentados na tabela 3. Nas parcelas onde houve o uso da fertirrigação, os teores de zinco no solo foram mais elevados e diferentes significativamente em relação às parcelas em que não foi realizada a fertirrigação. De forma oposta a anterior, a saturação por bases foi mais elevada nas parcelas sem o uso da fertirrigação em relação àquelas com o uso da fertirrigação. $\mathrm{O}$ menor valor médio de $\mathrm{pH}$ foi observado nas parcelas onde houve o uso da fertirrigação, ou seja, a utilização da técnica causou um decréscimo do $\mathrm{pH}$, provocando maior acidificação do solo. Teixeira et al. (2007) estudando as alterações nos atributos químicos do solo sob cultivo de bananeira em função da fertirrigação, também verificaram que o uso da técnica aumentou a acidez do solo.

Tabela 3. Teores médios de zinco, saturação por bases e pH do solo em função da fertirrigação

\begin{tabular}{cccc}
\hline Fertirrigação & $\begin{array}{c}\text { Zinco } \\
\left(\mathrm{mg} \mathrm{dm}^{-3}\right)\end{array}$ & $\begin{array}{c}\text { Saturação por } \\
\text { bases (\%) }\end{array}$ & $\mathrm{pH}$ \\
\hline Com & $1,1 \mathrm{a}$ & $42,9 \mathrm{~b}$ & $5,17 \mathrm{~b}$ \\
Sem & $0,8 \mathrm{~b}$ & $46,9 \mathrm{a}$ & $5,25 \mathrm{a}$
\end{tabular}

Médias seguidas pela mesma letra na coluna para um mesmo atributo não diferem entre si, ao nível de 5\%, pelo teste de Scott-Knott.

$\mathrm{O}$ aumento do $\mathrm{pH}$ do solo diminui a disponibilidade do zinco às plantas (Abreu, et al., 2007; Borges e Coutinho, 2004), devido a 
redução da solubilidade deste elemento com valores altos de $\mathrm{pH}$ do solo (Dynia e Barbosa Filho, 1993). A análise química do solo para a determinação do zinco foi realizada com solução Mehlich ${ }^{-1}$, verificando que a menor disponibilidade de zinco ocorreu nas parcelas sem o uso da fertirrigação, devido, principalmente, ao valor mais elevado do $\mathrm{pH}$ do solo. Também foi verificado por Accioly et al. (2004) que o aumento do $\mathrm{pH}$ do solo promoveu uma redução do zinco disponível analisado com solução Mehlich ${ }^{-1}$. Barros et al. (2010) também atribuiu à menor concentração de alguns micronutrientes no perfil do solo, dentre eles o zinco, pela elevação do $\mathrm{pH}$ do solo, que diminuiu a solubilização desse íon (Tabela 3).

Na tabela 4 visualiza-se os teores médios de manganês e hidrogênio + alumínio, a capacidade de troca catiônica, matéria orgânica e $\mathrm{o} \quad \mathrm{pH}$ do solo das camadas superficial $(0$ a $0,30 \mathrm{~m})$ e subsuperficial $(0,30$ a 0,60 m). As variáveis analisadas apresentaram comportamentos distintos nas duas camadas de solo, sendo que para manganês, hidrogênio + alumínio, capacidade de troca catiônica e matéria orgânica observou-se que a camada superficial apresentou valores médios mais elevados e diferentes estatisticamente em relação à camada mais profunda (subsuperficial). Por outro lado, foi constatado em superfície menor $\mathrm{pH}$ do solo em relação à camada subsuperficial.
Tabela 4. Teores médios de manganês, hidrogênio + alumínio $(\mathrm{H}+\mathrm{Al})$, capacidade de troca catiônica (CTC), matéria orgânica do solo (MO) e $\mathrm{pH}$ do solo nas camadas superficial $(0$ a $0,30 \mathrm{~m})$ e subsuperficial $(0,30$ a0,60 m)

\begin{tabular}{ccc}
\hline $\begin{array}{c}\text { Atributo } \\
\text { químico }\end{array}$ & \multicolumn{2}{c}{ Camada } \\
\hline $\begin{array}{c}\text { Manganerficial } \\
\left(\mathrm{mg} \mathrm{dm}^{-3}\right)\end{array}$ & $18,1 \mathrm{a}$ & Subsuperficial \\
$\begin{array}{c}\mathrm{H}+\mathrm{Al} \\
\left(\mathrm{cmol}_{\mathrm{c}} \mathrm{dm}^{-3}\right)\end{array}$ & $6,7 \mathrm{a}$ & $2,8 \mathrm{~b}$ \\
$\begin{array}{c}\mathrm{CTC} \\
\left(\mathrm{cmol}_{\mathrm{c}} \mathrm{dm}^{-3}\right)\end{array}$ & $6,7 \mathrm{a}$ & $5,0 \mathrm{~b}$ \\
$\begin{array}{c}\mathrm{MO} \\
\left(\mathrm{g} \mathrm{dm}^{-3}\right)\end{array}$ & $23,6 \mathrm{a}$ & $18,4 \mathrm{~b}$ \\
$\mathrm{pH}$ & $5,14 \mathrm{~b}$ & $5,29 \mathrm{a}$ \\
\hline
\end{tabular}

Médias seguidas pela mesma letra na linha não diferem entre si, ao nível de 5\%, pelo teste de Scott-Knott.

Em estudos utilizando a técnica de fertirrigação, teores mais elevados de matéria orgânica do solo nas camadas superficiais também foram observados por Peixoto et al. (2006) e Barros et al. (2010), com cultivo de coqueiro anão e cana-de-açúcar, respectivamente. O maior teor de matéria orgânica do solo na camada superficial contribuiu com a elevação da capacidade de troca catiônica observada nesta camada, causando desta forma a redução dos riscos de perdas dos cátions por lixiviação. Isso porque a capacidade de troca catiônica está intimamente ligada às concentrações dos íons trocáveis presentes na solução do solo e aos sítios de troca, e, a matéria orgânica, embora represente em média 5\% dos componentes sólidos, é responsável por cerca de $30 \%$ a $65 \%$ da capacidade de troca catiônica dos solos minerais (MATOS et al., 1996; SODRE et al., 2001).

Os menores teores de manganês disponível na camada mais profundidade $(0,30$ 
a $0,60 \mathrm{~m}$ ) pode ter sido favorecido pelo maior $\mathrm{pH}$ do solo nesta camada, uma vez que, em condições normais, o fator mais importante que controla a disponibilidade do manganês para as plantas é a reação do solo, decrescendo com a elevação do pH (Zanão Júnior et al., 2007).

Na tabela 5 são apresentados os teores médios de hidrogênio + alumínio e a capacidade de troca catiônica do solo em função da interação entre os níveis de reposição hídrica e fertirrigação. Nos tratamentos com o uso da fertirrigação, foram encontrados teores superiores estatisticamente de hidrogênio + alumínio no solo em associação com 25\% de reposição hídrica. Por outro lado, nos tratamentos sem o uso da fertirrigação, a associação com 50 e 75\% de reposição hídrica apresentaram teores mais elevados, estatisticamente, de hidrogênio + alumínio no solo.

A capacidade de troca catiônica do solo apresentou comportamento distinto quando comparados os tratamentos com e sem fertirrigação. Nas parcelas com o uso da fertirrigação, os valores mais elevados de capacidade de troca catiônica foram observados em associação com 25 e 75\% reposição hídrica. Entretanto, sem o uso da fertirrigação, as parcelas com 50, 75 e 100\% de reposição hídrica apresentaram os maiores valores de capacidade de troca catiônica, enquanto a parcela com aplicação de 25\% de reposição hídrica apresentou valor semelhante à parcela em que não foi utilizada a irrigação $(0 \%$ de reposição hídrica) (Tabela 5).
Tabela 5. Teores médios de hidrogênio + alumínio $(\mathrm{H}+\mathrm{Al})$ e capacidade de troca catiônica (CTC) no solo em função dos diferentes níveis de reposição hídrica, com e sem fertirrigação.

\begin{tabular}{ccc}
\hline $\begin{array}{c}\text { Reposição hídrica } \\
(\%)\end{array}$ & \multicolumn{2}{c}{ Fortirrigação } \\
\hline & $\mathrm{H}+\mathrm{Al}\left(\mathrm{cmol}_{\mathrm{c}} \mathrm{dm}^{-3}\right)$ & Sem \\
0 & - & 2,6 \\
25 & $4,0 \mathrm{~A}$ & $2,6 \mathrm{~B}$ \\
50 & $2,9 \mathrm{~B}$ & $3,5 \mathrm{~A}$ \\
75 & $3,3 \mathrm{~A}$ & $3,6 \mathrm{~A}$ \\
100 & $3,4 \mathrm{~A}$ & $3,0 \mathrm{~A}$ \\
\hline & $\mathrm{CTC}\left(\mathrm{cmol}_{\mathrm{c}} \mathrm{dm}^{-3}\right)$ & 4,8 \\
25 & - & $5,1 \mathrm{~B}$ \\
50 & $6,8 \mathrm{~A}$ & $6,2 \mathrm{~A}$ \\
75 & $5,5 \mathrm{~A}$ & $6,6 \mathrm{~A}$ \\
100 & $6,2 \mathrm{~A}$ & $6,0 \mathrm{~A}$ \\
\hline
\end{tabular}

Médias seguidas pela mesma letra maiúscula na linha para um mesmo atributo não diferem entre si, ao nível de 5\%, pelo teste de Scott-Knott.

É apresentado na figura 4 os teores médios de hidrogênio + alumínio $(\mathrm{H}+\mathrm{Al})$ e capacidade de troca catiônica (CTC) no solo em função dos diferentes níveis de reposição hídrica, com e sem fertirrigação. Assim como para os teores de cobre e ferro (Figura 3), os teores de $\mathrm{H}+\mathrm{Al}$ e CTC apresentaram um comportamento quadrático em função da lâmina irrigada, porém, verificou-se um comportamento inverso entre parcelas fertirrigadas e não fertirrigadas. Parcelas sem fertirrigação apresentaram um comportamento crescente de $\mathrm{H}+\mathrm{Al}$ e CTC até 66 e $77 \%$ da lâmina de irrigação, sendo que a partir desta lâmina os valores de $\mathrm{H}+\mathrm{Al}$ e CTC diminuíram. Já as parcelas com a utilização de fertirrigação os maiores valores para $\mathrm{H}+\mathrm{Al}$ e CTC foram encontrados quando se utilizou a menor lâmina de irrigação (25\%). Os menores valores encontrados no solo para $\mathrm{H}+\mathrm{Al}$ e CTC foram 
verificados na aplicação de 69 e 84\% de lâmina de irrigação.


Figura 4. Teores médios de hidrogênio + alumínio $(\mathrm{H}+\mathrm{Al})$, matéria orgânica e capacidade de troca catiônica (CTC) no solo em função dos diferentes níveis de reposição hídrica, com e sem fertirrigação.

Devido às alterações dos teores de micronutrientes e na acidez no solo em função dos tratamentos utilizados, nota-se que os teores médios de cobre, ferro e manganês foram considerados altos. Por outro lado, o zinco e o $\mathrm{pH}$ do solo apresentaram valores considerados médios e por fim, os teores de boro e a saturação por bases do solo foram considerados baixos (Raij et al., 1997).

\section{CONCLUSÕES}

O uso da fertirrigação combinada com diferentes lâminas de reposição hídrica promoveram alterações químicas no solo, tanto no aspecto de reação do solo quantos nos teores de micronutrientes.

O fator nível de reposição hídrica causou efeito significativo na alteração dos teores de cobre, ferro, hidrogênio + alumínio e capacidade de troca catiônica. A fertirrigação influenciou significativamente os teores de zinco, hidrogênio + alumínio, saturação por bases e pH no solo, sendo que provocou maior acidificação do solo.

As maiores alterações nos atributos químicos do solo foram observadas em função das camadas do solo analisadas. O uso da fertirrigação proporcionou maiores rendimentos de produtividade à cana-de-açúcar.

\section{AGRADECIMENTOS}

Os autores agradecem ao Ministério da Ciência e Tecnologia (MCT), ao Conselho Nacional de Desenvolvimento Científico e Tecnológico (CNPq), à Coordenação de Aperfeiçoamento de Pessoal de Nível Superior (CAPES), à Financiadora de Estudos e Projetos (FINEP) e à Fundação de Amparo à 
Pesquisa do Estado de Goiás (FAPEG) pelo apoio financeiro.

\section{REFERÊNCIAS BIBLIOGRÁFICAS}

ABREU, C.A.; LOPES, A.S.; SANTOS, G.C.G. Micronutrientes. In: NOVAIS, R.F.; ALVAREZ, V.H.; BARROS, N.F.; FONTES, R.L.F.; CANTARUTTI, R.B.; NEVES, J.C.L. (Eds.) Fertilidade do solo. Viçosa: Sociedade Brasileira de Ciência de Solo, 2007, p.471550.

ACCIOLY, A. M. A.; SIQUEIRA, J. O.; CURI, N.; MOREIRA, F. M. S. Amenização do calcário na toxidez de zinco e cádmio para mudas de Eucalyptus camaldulensis cultivadas em solo contaminado. Revista Brasileira de Ciência do Solo, Campinas, v. 28, p. 775-783, 2004.

ANDRADE JÚNIOR, A. S.; BASTOS, E. A.; RIBEIRO, V. Q.; DUARTE, J. A. L.; BRAGA, D. L.; NOLETO D. H. Níveis de água, nitrogênio e potássio por gotejamento subsuperficial em cana-de-açúcar. Pesquisa Agropecuária Brasileira, Brasília, v.47, n.1, p.76-84, 2012.

BARROS, R. P.; VIÉGAS, P. R. A.; SILVA, T. L.; SOUZA, R. M.; BARBOSA, L. VIÉGAS, R. A; BARRETTO, M. C. V.; MELO, A. S. Alterações em atributos químicos de solo cultivado com cana-deaçúcar e adição de vinhaça. Pesquisa Agropecuária Tropical, v. 40, n. 3, p. 341-346, 2010.

BATAGLIA, O.C.; MASCARENHAS, H.A.A Toxicidade de ferro em soja. Bragantia, 40:199-203, 1981 (nota, 5).

BORGES, M.R.; COUTINHO, E.L.M. Metais pesados do solo após aplicação de biossólido:
II - Disponibilidade. Revista Brasileira de Ciência do Solo, v.28, p.557-568, 2004.

BURT, C.; O’CONNOR, K.; RUEHR, T. Fertigation. San Luis Obispo: California Polytechnic State University/Irrigation Training and Research Center, 1995. 295p.

CASTRO NETO, P. Notas de aula prática do curso de agrometeorologia. Lavras, ESAL, 1982. 45p.

DALRI, A.B.; CRUZ, R.L. Produtividade da cana-de-açúcar fertirrigada com $\mathrm{N}$ e $\mathrm{K}$ via gotejamento subsuperficial. Engenharia Agrícola, v. 28, p. 516-524, 2008.

DUENHAS, L.H.; VILLAS BÔAS, R.L.; SOUZA, C.M.P.; RAGOZO, C.R.A.; BULL, L.T. Fertirrigação com diferentes doses de NPK e seus efeitos sobre a produção e qualidade de frutos de laranja (Citrus sinensis O.) 'Valência'. Revista Brasileira de Fruticultura, v. 24, n. 1, p. 214-218, 2002.

DYNIA, J.F.; BARBOSA FILHO, M.P. Alterações de $\mathrm{pH}$, Eh e disponibilidade de micronutrientes para o arroz irrigado em um solo de várzea tratado com calcário e palha de arroz em casa de vegetação. Revista Brasileira da Ciência do Solo, 17:67-74, 1993.

EMPRESA BRASILEIRA DE PESQUISA AGROPECUÁRIA (Embrapa). Centro Nacional de Pesquisa de Solos. Manual de métodos de análise de solos. 2. ed. Rio de Janeiro: Embrapa, 1997.

EMPRESA BRASILEIRA DE PESQUISA AGROPECUÁRIA. Sistema brasileiro de classificação de solos. 2.ed. Rio de Janeiro: Ministério da Agricultura e do abastecimento, 2006. 306p.

FAGERIA N. K. Otimização da eficiência nutricional na produção das culturas. Revista Brasileira de Engenharia Agrícola Ambiental, v. 2, p.6-16, 1998. 
FERREIRA, D. Manual do sistema Sisvar para análises estatísticas. Lavras: UFLA, 2000. p. 66.

GLASS, A.D.M. Plant nutrition: an introduction to current concepts. Boston: Jones and Bartlett Publishers, 1989. 234 p.

MAPA, Ministério da Agricultura, Pecuária e Abastecimento. Cana-de-açúcar. Disponível em: <http://www.agricultura.gov.br/vegetal/ culturas/cana-de-acucar $>$. Acesso em 02 abril de 2013.

MARSCHNER, H. Mineral nutrition of higher plants. 2th. London: Academic Press, 1995. 889 p.

MATOS, A.T.; FONTES, M.P.F.; JORDÃO, C.P.; COSTA, L.M. Mobilidade e formas de retenção de metais pesados em Latossolo Vermelho-Amarelo. Revista Brasileira da Ciência do Solo, v. 20, p. 379-386, 1996.

PADILLA, W.A. Factores que limitan el crescimiento y desarrollo de las plantas. Segundo Curso Internacional de Fertirrigacion en cultivos protegidos. Universidade San Francisco de Quito, Quito - Ecuador, Maio 1998, p.1-10.

PEIXOTO, J. F. S.; GUERRA, H. O. C.; CHAVES, L. H. G. Alterações de atributos químicos do solo pela fertirrigação com nitrogênio e potássio. Agropecuária Técnica, v.27, n.2, p.69-76, 2006.

RAIJ, B. van; CANTARELLA, H.; QUAGGIO, J.A.; FURLANI, A.M.C. (Ed.). Recomendações de adubação e calagem para o Estado de São Paulo. Campinas: Fundação IAC, 1997. p.233-243. (Boletim, 100).

SCOTT, A. J.; KNOTT, M. Accounter analysis methods for grouping means in the analysis of variants. Biometrics, Washington, v. 30, p. 507-512, 1974.

SODRE, F.F.; LENZI, E.; COSTA, A.C.S. Utilização de modelos físico-químicos de adsorção no estudo do comportamento do cobre em solos argilosos. Química Nova, v. 24, n. 3, p. 324-330, 2001.

SOUSA, D.M.G.; LOBATO, E. Cerrado: Correção do solo e adubação. 2.ed. Brasília, Embrapa Informação Tecnológica, 2004. 416 p.

TEIXEIRA, L.A.J.; MARTINS, A.L.M.; NATALE, W.; BETTIOL NETO, J.E. Nitrogênio e potássio em bananeira via fertirrigação e adubação convencionalatributos químicos do solo. Revista Brasileira de Fruticultura, Jaboticabal, v.29, n.1, p.143152, 2007.

TEIXEIRA, L.A.J.; NATALE, W.; BETTIOL NETO, J.E.; MARTINS, A.L.M. Nitrogênio e potássio em bananeira via fertirrigação e adubação convencional-atributos químicos do solo. Revista Brasileira de Fruticultura, vol. 29, n.1, 2007.

VETTORI, L. Métodos de análise de solo. Rio de Janeiro: Ministério da Agricultura, EPF, 1969, 24p. (Boletim Técnico, 7).

VIEIRA, R.F. Quimigação e fertigação. In: VIEIRA, C.; PAULA JÚNIOR, T.J. de; BORÉM, A. Feijão: aspectos gerais e culturais no Estado de Minas. Viçosa, MG: Ed. UFV, 1998. p.221-266.

ZANÃO JÚNIOR, L.A.; LANA, R.M.Q.; GUIMARÃES, E.C. Variabilidade espacial do $\mathrm{pH}$, teores de matéria orgânica e micronutrientes em profundidade em um Latossolo Vermelho sob semeadura direta. Ciência Rural, v. 37, p. 1000-1007, 2007. 